\title{
Correction to: A general branch-and-bound framework for continuous global multiobjective optimization
}

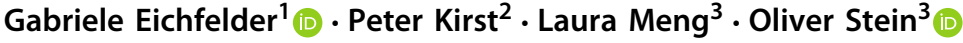

Published online: 23 February 2021

(c) TheAuthor(s) 2021

\section{Correction to: Journal of Global Optimization https://doi.org/10.1007/s10898-020-00984-y}

The publisher introduced an error in the last sentence of the proof for Lemma 3.2. Its beginning "The supremum of $\widetilde{W}(L B, U B)$ " must be replaced by "The supremum of $\bar{W}(L B, U B)$ ". The original article has been corrected.

Publisher's Note Springer Nature remains neutral with regard to jurisdictional claims in published maps and institutional affiliations.

The original article can be found online at https://doi.org/10.1007/s10898-020-00984-y.

Oliver Stein

stein@kit.edu

Gabriele Eichfelder

gabriele.eichfelder@tu-ilmenau.de

Peter Kirst

peter.kirst@wur.nl

Laura Meng

laura.meng@web.de

1 Institute for Mathematics, Technische Universität Ilmenau, Ilmenau, Germany

2 Operations Research and Logistics (ORL), Wageningen University and Research (WUR),

Wageningen, The Netherlands

3 Institute of Operations Research (IOR), Karlsruhe Institute of Technology (KIT), Karlsruhe, Germany 